\title{
Design and evaluation of silage equipment control panel based on the theory of emotional design and Kansei Engineering
}

\author{
Jie Yan, Bing Lva ${ }^{\mathrm{a}}$, Jianqiang Wang, Derong Duan, Mengjia Chen and Zequn Li \\ University of Jinan, School of Mechanical Engineering, 250022 Jinan Shandong, China
}

\begin{abstract}
In order to make the silage equipment control panel meet user needs better and translate user requirements into product design elements, this paper puts forward the design model of silage equipment control panel based on the theory of emotional design and Kansei Engineering. Firstly, qualitative and quantitative analyses of silage equipment control panel were conducted according to the results of the user survey. Then, the prior design elements and the "Feature-Vocabulary" correspondence were obtained, which were applied to the design of silage equipment control panel. Finally, the design plan was evaluated using semantic differential method. As a result, it is initially verified that the design model has certain feasibility for translating user requirements into product design elements.
\end{abstract}

\section{Introduction}

Today, the "people-oriented" design concept is gradually accepted by people and is successfully verified on more and more product designs. With the rapid development of science and technology and the continuous improvement of the quality of life, the factors that determine whether a product can fully reflect its value are gradually changing from functions to satisfying user's aesthetic appeal and a higher level of emotional appeal. Therefore, it requires designers to fully study user needs in the early stage of product design and design process in order to meet user's appeal. Starting from the theory of emotional design and Kansei Engineering can make us better understand user needs and provide guidance for emotional design. The theory of emotional design emphasizes the design research based on user's spiritual needs. The layers of instinct, behavior, and reflection play different roles in the use of products. Moreover, each layer was achieved using different methods [1], which provides designers with a vast creative space [2]. Scholars tried to convert user's psychological and emotional needs into specific design elements starting from the perspective of users [3-8]. In terms of human-machine interaction of silage equipment, the control panel, as an important part of the operated device, integrates the main control components of the silage equipment. This paper combines the theory of emotional design and Kansei Engineering to conduct the user emotional survey of silage equipment control panel. Moreover, the analysis results were applied to the design plan. Finally, the plan was evaluated to prove the feasibility of the research method.

\section{Research Methods}

Qualitative and quantitative research methods are basic and important methods in the field of social science and scientific research [9]. Qualitative and quantitative research methods were used comprehensively to put forward the design model of silage equipment control panel (as shown in Figure 1). Firstly, qualitative and quantitative analyses of silage equipment control panel were conducted according to the results of the user survey. Then, the existing problems of design elements, the prior design elements and the "Feature-Vocabulary" correspondence were summarized, which were applied to the design of silage equipment control panel. Finally, the design plan was evaluated using semantic differential method.

The first author: Jie Yan E-mail: jiejie_1488@qq.com *Corresponding author: ${ }^{a}$ Bing Lv E-mail: me_lvb@ujn.edu.cn 


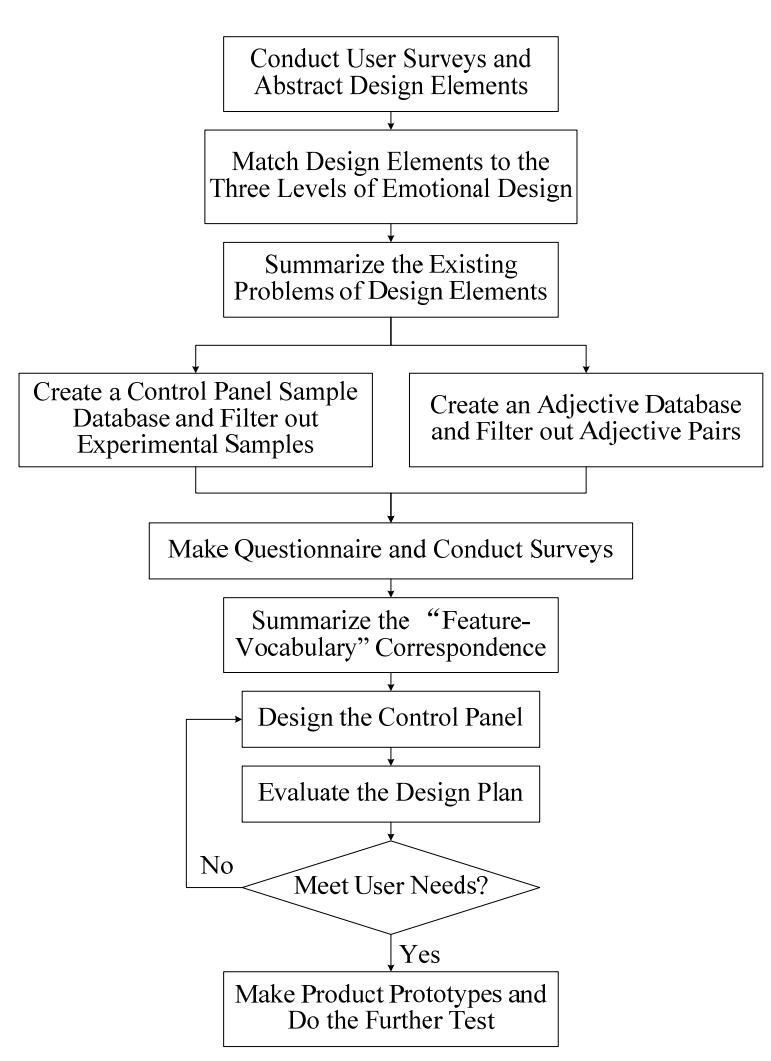

Figure1. Design Model of Silage Equipment Control Panel

\section{Qualitative Research of Control Panel}

Before the quantitative research, the qualitative research is necessary. The purpose is usually to make hypotheses or determine the stimuli of the study. Its depth and breadth of problem description are beyond quantitative research. The results of user surveys were combined with three-layer of emotional design to extract and classify the design elements of the control panel. Then the existing problems of the design elements were summarized.

\subsection{Control Panel Design Elements Extraction and Classification}

The emotional design proposed by Norman believes that when users use the product, they will have three layers of sensibility which are instinct layer, behavior layer, and reflection layer. They have different characteristics, factors and research methods. The design of the instinct layer is related to human's first reaction. The physiological characteristics such as vision, feeling, and sound play the main roll. The influencing factors include the shape, color, touch and weight of the product. The design of the behavior layer is related to human's feelings when using the product. The influencing factors include function, ease of use, comprehensibility and feelings. Professor Norman believes that it is difficult for users to express their needs clearly, and the way to find these needs is observation. Designers are required to discover user needs and got solutions when the product is used naturally. The design of the reflection layer is related to the culture, information and meanings of the product, and emotion and self-image aroused by products. The influencing factors include product semantics, self-image, memories and so on. The real value of products lies not only in the realization of functions, but also in satisfying the emotional needs of users, establishing self-image, highlighting personal taste and social status.

First of all, the observation method was used to pay attention to the words, actions, eyes, expressions and postures of target users (farmers, professional silage workers and manufacturers), who were using different silage equipment control panels (different in forms, colors, location layouts, etc.) naturally. Then users' feelings and evaluations were asked and noted. After that, the design elements of each part of the control panel were extracted according to the principles from the whole to the part. Based on the definitions of the three-layer of the emotional design, the correspondence (as shown in Table 1) of the design elements of each part and the three-layer of emotional design was obtained for follow-up study.

\subsection{Analyses of the Design Elements Problems}

Data shows that silage equipment control panel lacks in human-machine interaction design. Users do not be satisfied enough with products which do not consider users physiological and psychological factors fully [10]. There are some requirements of design elements such as the shape and installation position of the control panel, the shape and layout of the hand manipulators, and the location and promptness of the icons (as shown in Table 2 ). The lack of these element designs leads to the decrease of users understanding and operating efficiency of products, resulting in misoperation, inconvenience and even hidden dangers to health and safety.

\section{Quantitative Research of Control Panel}

The quantitative study was conducted based on the above analyses of the control panel design elements and existing problems.

Image Scale Method is a quantitative research method commonly used, which can be used to measure and analyse people's cognitive psychology of products. Image Scale Method is based on semantic differential method. It requires the researcher to collect vocabularies that can describe style characteristics of the research object to make a semantic analysis scale. This scale contains pairs of adjectives that are antisense to each other as two poles. Each pair of adjectives divided into seven grades on average to form a seven-grade scale. The closer the grade to a vocabulary is, the closer it is to the description of the vocabulary. Users were required to choose a certain grade to express their own perceptions and feelings. Combining semantic differential method and questionnaire method in quantitative research, the user survey on silage equipment control panel was conducted. The prior design elements and the "Feature-Vocabulary" correspondence were obtained. 
Table 1. Correspondence Between Control Panel's Design Elements and the Three-Layer of Emotional Design

\begin{tabular}{|c|c|c|c|c|c|c|c|c|c|}
\hline \multirow{2}{*}{ Design Elements } & \multicolumn{3}{|c|}{ Instinct Layer } & \multicolumn{3}{c|}{ Behavior Layer } & \multicolumn{3}{c|}{ Reflection Layer } \\
\cline { 2 - 11 } & Panel & Manipulator & Icon & Panel & Manipulator & Icon & Panel & Manipulator & Icon \\
\hline Form & $\bullet$ & $\bullet$ & $\bullet$ & $\bullet$ & $\bullet$ & $\bullet$ & $\bullet$ & $\bullet$ & $\bullet$ \\
\hline Color & $\bullet$ & $\bullet$ & $\bullet$ & $\bullet$ & $\bullet$ & $\bullet$ & $\bullet$ & $\bullet$ & $\bullet$ \\
\hline Material & $\bullet$ & $\bullet$ & $\bullet$ & & & & $\bullet$ & $\bullet$ & $\bullet$ \\
\hline Function & & & & $\bullet$ & $\bullet$ & $\bullet$ & & & \\
\hline Location & & & & $\bullet$ & $\bullet$ & $\bullet$ & & & \\
\hline
\end{tabular}

\subsection{Early Preparation}

\subsubsection{Filtering out Experimental Samples}

After collecting a large of samples of silage equipment control panel with high user satisfaction, the control panel database was established (as shown in Figure 2).material and layout was removed. Then the six experimental samples was filtered out for subsequent questionnaire surveys (as shown in Figure 3).

Table 2. Problems Analyses of Control Panel Design Elements

\begin{tabular}{|c|l|}
\hline Contents & \multicolumn{1}{|c|}{ Problems } \\
\hline $\begin{array}{c}\text { Control } \\
\text { Panel }\end{array}$ & $\begin{array}{l}\text { Single form } \\
\text { Missing detail design } \\
\text { Heavy use of metal }\end{array}$ \\
\hline $\begin{array}{c}\text { Functional } \\
\text { Area Layout }\end{array}$ & $\begin{array}{l}\text { Not obvious to distinct } \\
\text { Confused }\end{array}$ \\
\hline $\begin{array}{c}\text { Manipulator } \\
\text { Layout }\end{array}$ & Do not correspond with operations. \\
\hline Icons & $\begin{array}{l}\text { Not easy to observe. } \\
\text { Difficult to identify and understand. }\end{array}$ \\
\hline
\end{tabular}

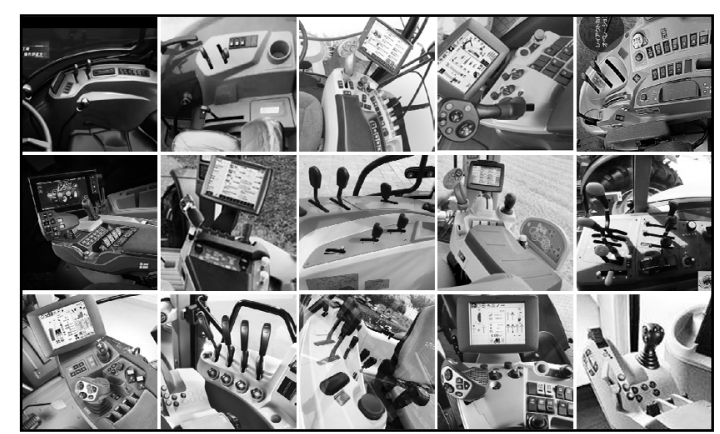

Figure2. Sample Database of the Control Panel (Partial)

\subsubsection{Filtering out Vocabularies and Making Scale}

After collating survey data and consulting documents, websites and magazines, the adjective database of the control panel containing descriptive vocabularies related to the control panel was created. The 15 pairs of bipolar adjectives recognized in the international consumer behavior field can define a product feature widely (as shown in Table 3). Then the neutral words and synonyms are removed through expert voting and discussion. Finally, 10 pairs of vocabulary words describing product feature of the control panel were filtered out. In addition, the "like-dislike" word pair was added for the investigation of the reflective layer to quantify the degree of resonance between the product image and user's emotion. The 11 groups of adjectives (as shown in Table 4) constituted a 7-grade scale for subsequent questionnaire survey.

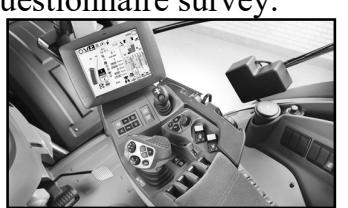

(1)

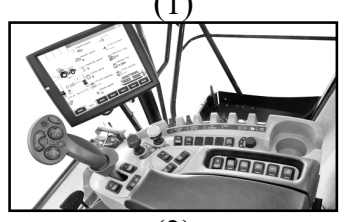

(3)

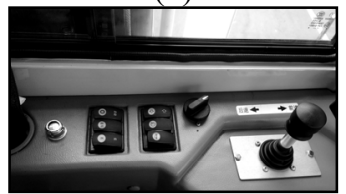

(5)

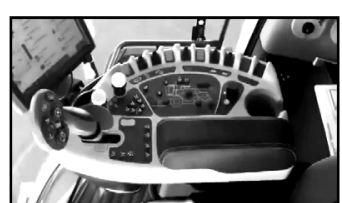

(2)

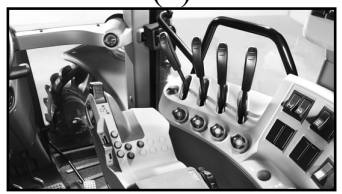

(4)

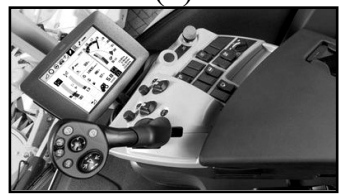

(6)
Figure3. Experimental Samples of the Control Panel

Table3. Bipolar Adjectives

\begin{tabular}{|c|c|c|c|}
\hline 1 & 2 & 3 & 4 \\
\hline $\begin{array}{c}\text { Clever } \\
\text { Rough }\end{array}$ & $\begin{array}{c}\text { Peaceful } \\
\text { Fierce }\end{array}$ & $\begin{array}{c}\text { Relaxed } \\
\text { Intense }\end{array}$ & $\begin{array}{c}\text { Delicate } \\
\text { Tough }\end{array}$ \\
\hline 5 & 6 & 7 & 8 \\
\hline $\begin{array}{c}\text { Implied } \\
\text { Exaggerate }\end{array}$ & $\begin{array}{c}\text { Funny } \\
\text { Serious }\end{array}$ & $\begin{array}{c}\text { Popular } \\
\text { Outdated }\end{array}$ & $\begin{array}{c}\text { Mainstream } \\
\text { Alternative }\end{array}$ \\
\hline 9 & 10 & 11 & 12 \\
\hline $\begin{array}{c}\text { Warm } \\
\text { Cold }\end{array}$ & $\begin{array}{c}\text { Mature } \\
\text { Childish }\end{array}$ & $\begin{array}{c}\text { Common } \\
\text { Bizarre }\end{array}$ & $\begin{array}{c}\text { Progressive } \\
\text { Conservativ } \\
\text { e }\end{array}$ \\
\hline 13 & 14 & 15 & \\
\hline $\begin{array}{c}\text { Concise } \\
\text { Complicated }\end{array}$ & $\begin{array}{c}\text { Gorgeous } \\
\text { Pure }\end{array}$ & $\begin{array}{c}\text { Realistic } \\
\text { Fantasy }\end{array}$ & \\
\hline
\end{tabular}

\subsection{Questionnaire Production and User Survey}

First of all, the questionnaire was set up a user feature question to determine whether the user who are filling in the questionnaire understands or has used the control panel. 
Then the questionnaire was set up a question of the design elements priority. The user was required to select four most important factors when using or purchasing products in order to obtain the prior design elements of the control panel.

Finally, the questionnaire was set up a question of

Table4. Experimental Adjectives

\begin{tabular}{|c|c|c|c|}
\hline \multicolumn{2}{|c|}{ Form } & \multicolumn{2}{c|}{ Color } \\
\hline 1 & 2 & 3 & 4 \\
\hline $\begin{array}{c}\text { Conservative } \\
\text { Progressive }\end{array}$ & $\begin{array}{c}\text { Stiff } \\
\text { Gentle }\end{array}$ & $\begin{array}{c}\text { Cold } \\
\text { Warm }\end{array}$ & $\begin{array}{c}\text { Intense } \\
\text { Relaxed }\end{array}$ \\
\hline \multicolumn{2}{|c|}{ Material } & \multicolumn{2}{c|}{ Function } \\
\hline 5 & 6 & 7 & 8 \\
\hline $\begin{array}{c}\text { Rough } \\
\text { Delicate }\end{array}$ & $\begin{array}{c}\text { Single } \\
\text { Diverse }\end{array}$ & $\begin{array}{c}\text { Simple } \\
\text { Abundant }\end{array}$ & $\begin{array}{c}\text { Incompre- } \\
\text { hensible } \\
\text { Understand- } \\
\text { able }\end{array}$ \\
\hline \multicolumn{2}{|c|}{ Location } & \multicolumn{2}{c|}{ Preference } \\
\hline 9 & 10 & \multicolumn{2}{c|}{11} \\
\hline $\begin{array}{c}\text { Complicated } \\
\text { Concise }\end{array}$ & $\begin{array}{c}\text { Confused } \\
\text { Clear }\end{array}$ & \multicolumn{2}{c|}{$\begin{array}{c}\text { Dislike } \\
\text { Like }\end{array}$} \\
\hline
\end{tabular}

7-grade scales of control panel samples. One scale was next to one sample (as shown in Figure 4).

Questionnaires were distributed to the target users, and users are provided with a brief explanation such as the questionnaire's structure and the rule to fill.

As a result, 41 questionnaires was collected. After removing invalid questionnaires (the user is unfamiliar with silage equipment control panel, 40 valid questionnaires was obtained.

\subsection{Statistics and Analyses of Survey Results}

Each grade in the 7-grade scale was counted from one to seven points. Then the average scores was calculated. As a result, the user's cognitive adjectives of each sample was obtained. Such as "conservative-progressive", if the average score is less than 4 points, it is conservative. If the average score is 4 points, it is neutral. If the average score is more than 4 points, it is progressive.

Statistically, adjectives of sample 1 are "progressive and stiff", "cold and relaxed", "delicate and diverse", "abundant and understandable" and "complicated and clear". Adjectives of Sample 2 are "progressive and gentle", "warm and intense", "delicate and diverse", "abundant and understandable" and "concise and confused". Adjectives of Sample 3 are "progressive and gentle", "warm and relaxed", "delicate and diverse", "abundant and incomprehensible" and "complicated and confused". Adjectives of Sample 4 are "progressive and stiff", "warm and relaxed", "delicate and single", "abundant and understandable" and "concise and confused". Adjectives of Sample 5 are "conservative and stiff", "cold and relaxed", "delicate and single", "abundant and complicated" and "concise and clear". Adjectives of Sample 6 are "progressive and gentle", "warm and relaxed", "delicate and single", "abundant and complicated" and "concise and clear".

User's favorite sample is sample 1. The most important elements are the function of the control panel and the layout of the manipulators. These two elements were considered first in the design process.

\subsection{Feature-Vocabulary Correspondence}

According to the user's favorite sample and corresponding adjectives, the line diagram of the layout was extracted. In accordance with "point-line-surface-body" and "details - the whole" orders, the "Feature-Vocabulary" correspondence of other design elements was summarized (as shown in Table 5). The following work was based on this.

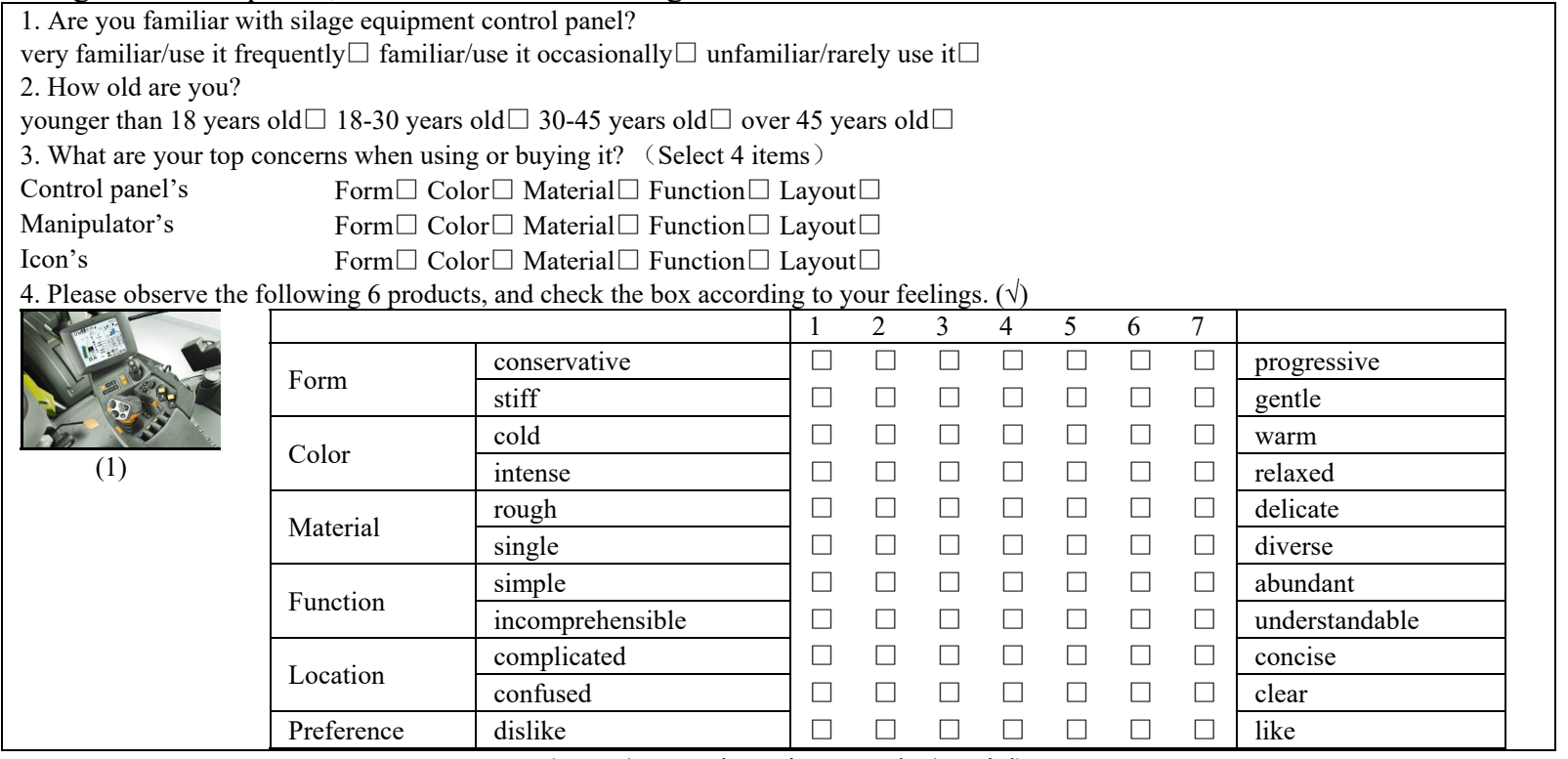

Figure4. Questionnaire Sample (Partial) 
Table5. "Feature-Vocabulary" Correspondence of User's Favorite Sample

\begin{tabular}{|c|c|c|c|c|c|}
\hline \multirow{2}{*}{\multicolumn{2}{|c|}{ Adjective }} & \multicolumn{4}{|c|}{ Feature } \\
\hline & & \multicolumn{2}{|c|}{ Control Panel } & \multirow{3}{*}{\begin{tabular}{l}
\multicolumn{1}{c}{ Manipulator } \\
Square; Round; Polygonal; \\
Polyhedron; Conform
\end{tabular}} & \multirow{3}{*}{\begin{tabular}{l}
\multicolumn{1}{c}{ Icon } \\
Pattern; Scale; \\
Direction \\
\end{tabular}} \\
\hline \multirow{2}{*}{ Form } & Progressive & \multirow{2}{*}{\multicolumn{2}{|c|}{$\begin{array}{l}\text { Small rounded corners; Straight lines; Large } \\
\text { curved surfaces; Facets; Squares }\end{array}$}} & & \\
\hline & Stiff & & & & \\
\hline \multirow{2}{*}{ Color } & Cold & \multirow{2}{*}{\multicolumn{2}{|c|}{ Gray; White; Color embellishment }} & \multirow{2}{*}{$\begin{array}{l}\text { Black; Gray; Orange; } \\
\text { Color distinguish }\end{array}$} & \multirow{2}{*}{ White } \\
\hline & Relaxed & & & & \\
\hline \multirow{2}{*}{$\begin{array}{c}\text { Materi } \\
\text { al }\end{array}$} & Delicate & \multirow{2}{*}{\multicolumn{2}{|c|}{ Plastic; Cloth; Rubber }} & \multirow{2}{*}{$\begin{array}{l}\text { Plastic; Rubber; Polishing; } \\
\text { Matte }\end{array}$} & \multirow{2}{*}{ Screen printing } \\
\hline & Diverse & & & & \\
\hline \multirow{2}{*}{$\begin{array}{c}\text { Functi } \\
\text { on }\end{array}$} & Abundant & \multirow{2}{*}{\multicolumn{2}{|c|}{ Integration; Partitioning }} & \multirow{2}{*}{$\begin{array}{l}\text { Push; Pull; Press; Screw; } \\
\text { Ergonomic }\end{array}$} & Correspondence; \\
\hline & Understandable & & & & Tip \\
\hline \multirow{2}{*}{ Layout } & Complicated & \multirow{3}{*}{\multicolumn{2}{|c|}{ 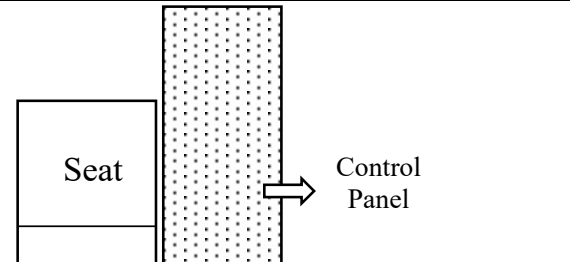 }} & \multirow[t]{3}{*}{ 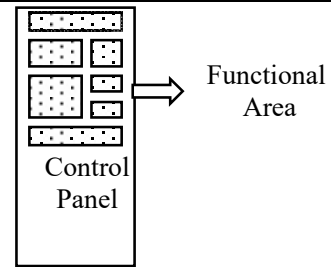 } & $\underset{\Gamma}{\Rightarrow}$ Icon \\
\hline & Clear & & & & $\begin{array}{l}\text { Top Surface of } \\
\text { Manipulator }\end{array}$ \\
\hline & & & & & \\
\hline
\end{tabular}

\section{Design Plan and Evaluation}

Based on the questions summarized in the qualitative research and the results of quantitative research, the following plan was put forward (as shown in Figure 7):

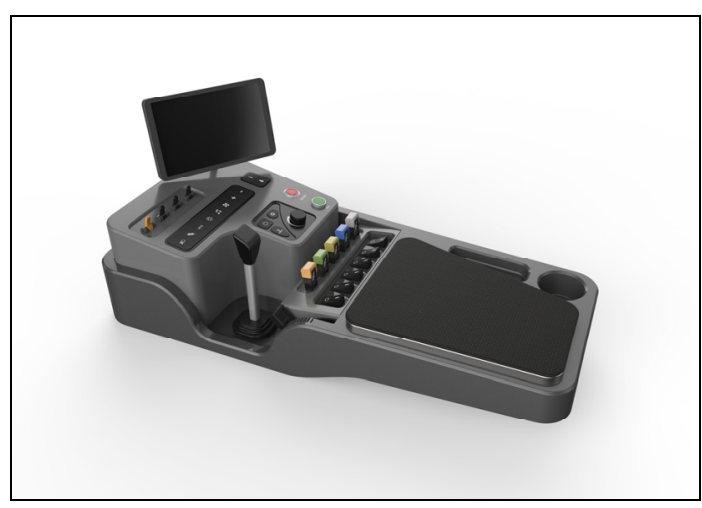

Figure7. Plan of Control Panel

The plan and the 7-grade scale were placed on the same page. The 40 target users were invited to judge the design plan and check each item. Statistically, the corresponding adjectives of the plan are "progressive and gentle", "cold and relaxed", "delicate and single", "abundant and understandable" and "concise and clear". The average score of the preference is 4.725 . It showed that the plan meets emotional needs of users and has a high degree of preference.

\section{Conclusion}

In this paper, the design model of silage equipment control panel was put forward based on the theory of emotional design and Kansei Engineering. Firstly, the observation method was adopt to extract the design elements of silage equipment control panel, then the problems existing in design elements were analysed qualitatively. Secondly, user research was conducted using semantic differential method and questionnaire method, then the prior design elements and the "Feature-Vocabulary" correspondence were obtained, which were applied to the design of silage equipment control panel. Finally, the design plan was evaluated using semantic differential method. Due to space limitations, this paper only discussed methods, processes, results and conclusions of study. The complete statistical results were not listed in full. Moreover, the investigation of the reflection layer focused on the preference only. In the follow-up work, quantifying product semantics and user self-images will be further studied. Product prototype will be created to conduct user testing.

\section{Acknowledgment}

Fund Project: 2017 Shandong Province Agricultural Machinery Research and Development and Innovation Plan Funding Project (2017YF004-10)

\section{References}

1. D.A. Norman, Emotional Design (China CITIC Press, Beijing, 2015)

2. H.X. Zhu, Y.Y. Zhang, B.W. Xu, J. Mach. Des, 4, 122-124 (2016)

3. J. Huang, D.H Xiao, Packag. Eng, 4, 218-222 (2017)

4. Z.Y. Wang, H.S. Liu, J. Graph, 30, 2, 126-129 (2009)

5. Y.F. Bi, N.W. Wang, Y.W. Zhu, Packag. Eng, 2, 160-165 (2018)

6. L.L. Sun, F.S. Kong, Y. Zhou, X.Y. Liu, Chinese J. Ergonom, 19, 2, 60-62 (2013)

7. J.Q. Zhang, Q.W. Hu, M. Ding, Ind. Des, 10, 63-64 (2015)

8. X. Meng, J.C. Wang, Journal of Donghua University(Natural Science), 34, 3, 299-302 (2008)

9. B.B. Li, Product Design Psychology Evaluation Research. (China Light Industry Press, Beijing, 2013)

10. B. Lv, J. Yan, J.Q. Wang, B. Yang, Z.Q. Li, J. Mach. Des, 34, S2, 122-124 (2017) 